\title{
Synthesis of Quinazolinyl Chalcone Derivatives
}

\author{
Heping Yan ${ }^{1,2, a}$, Jianguang Shi ${ }^{3}$, Gaozhang Gou ${ }^{1,2}$, Jucheng Zhang ${ }^{1,2}$, Dushu \\ Huang $^{1,2}$, Shijuan $\mathrm{Xu}^{1,2}$, Xuebin Chen ${ }^{1,2}$, Xuequan Wang ${ }^{1,2}$, Yong Hong ${ }^{1,2}$, \\ Wei Liu', ${ }^{1,2}$
}

${ }^{1}$ College of Science, Honghe University, Yunnan 661100, China;

${ }^{2}$ Key Laboratory of Natural Pharmaceutical and Chemical Biology of Yunnan Province, 661100, China;

${ }^{3}$ College of Politics and International Relations, Honghe University, Yunnan 661100, China

aemail-yhpyh19511@163.com

Keywords: 2-aminobenzonitrile; N,N-dimethylformamide dimethyl acetal; aminoa- cetophenone; paradimethylaminobenzaldehyde; chalcone; quinazoline

Abstract: 4-(4'-quinazolin-ylamino) phenyl-4-(N,N- dimethylamino) phenyl propenyl ketone with total yield of $68.0 \%$ was synthesized with 2-aminobenzonitrile and $\mathrm{N}, \mathrm{N}$-dimethylformamide dimethyl acetal as a starting material, the synthesis of N-(2-cyanophenyl)-N,N-dimethyl formamidine, and then amino acetophenone to form a ring, and finally reaction with formaldehyde dimethylaminobenzaldehyde. The experimental conditions were optimized. The results showed that: Intermediate 1 was synthesized by 2 -aminobenzonitrile and $\mathrm{N}, \mathrm{N}$ - dimethylformamide dimethyl acetal and their molar ratio of 1: 2, the optimal reaction temperature is $85{ }^{\circ} \mathrm{C}$. Intermediate 2 synthesized optimal temperature of $105{ }^{\circ} \mathrm{C}$. Intermediates and target compounds by ${ }^{1} \mathrm{H} \mathrm{NMR},{ }^{13} \mathrm{C}$ NMR and mass spectrometry for structural characterization.

\section{Introduction}

Quinazoline derivatives are a class of compounds containing quinazoline ring basic skeleton of these compounds with a wide range of biomedical activity, their unique physical and chemical properties play an important role in the development of Chinese medicine, and has been widely used in medicine pesticide fields. As for a tyrosine kinase inhibitor [1], it acts as the anti-tumor and anti-bacterial. From 1990 through 2013, the study of the transformation of the quinazoline skeleton and pharmacological activity in the pharmaceutical and chemical research in the field has maintained a growth trend, in which the 4-phenylbutyrate aminoquinazoline compound [2-10] quinazoline compounds in most species.

Chalcone and its derivatives are a class of compounds containing 1,3-diphenyl-propenone structure, modern pharmacological studies have shown chalcones have important pharmacological effects, including anti-oxidation, anti-mutagenic, anti-aging, and inhibition of platelet aggregation, lowering blood sugar, anti-HIV, anti-ulcer swing, liver and other effects [11]; anti-pinworm effects [12], anti-allergic effects [13], at the same time, it can be used as antibiotics, anti-cancer, antimalarial medicines [14]. On tumorigenesis, multiple stages of development have significant effects, including inhibition of tumor cell proliferation and induce tumor cell differentiation and apoptosis, and inhibition of tumorigenesis and metastasis [15].

In this paper, the active groups splicing was used as the synthesis method, 2-aminobenzonitrile and $\mathrm{N}, \mathrm{N}$ - dimethylformamide dimethyl acetal (DMF-DMA) as a starting material, after three steps, the synthesis of 4-(4'-quinazolinyl amino) phenyl-4-(N,N-dimethylamino) phenyl ketone compound propylene, realized the aminoquinazoline chalcone fragments and fragments spliced together active groups. 


\section{Expememtal}

\section{Apparatus and Reagents}

${ }^{1} \mathrm{H}$ NMR by JEOL-ECX 400MHz NMR (Japan Electronics Co., Ltd.), with TMS as internal standard, $\mathrm{CDCl}_{3}$, or DMSO- $d_{6}$ as solvent; melting point was determined by X-4 digital display micro melting point apparatus (thermometer uncorrected)) (Shanghai precision Scientific Instrument Co., Ltd. Manufacturing); ESI-MS was measured by LCMS-QP2010 gas chromatograph mass spectrometer (Shimadzu Corporation); weighing AR1140 digital electronic balance (Ohaus international Trading (Shanghai) Co., Ltd. ); rotary evaporation with N-1001 rotary evaporator (on Haiai Lang instrument Co., Ltd.); TLC with GF254 fluorescent silica plates (Qingdao Marine chemical Plant). The reagents used for the AR-made reagent grade, unless otherwise stated, are not treated directly.

\section{Synthesis of N '- (2- cyanophenyl) - N, N- dimethyl-formamidine}

$0.5524 \mathrm{~g}$ ( $4.7 \mathrm{mmol})$ of 2-aminobenzonitrile, $1.1142 \mathrm{~g}(9.4 \mathrm{mmoL})$ DMF-DMA was added into $25 \mathrm{~mL}$ three-neck flask, the three-necked flask is mounted on a magnetic stirrer, a thermometer is inserted, fitted with spherical condenser, heated to $85^{\circ} \mathrm{C}$. The beginning of the reaction liquid was light yellow, the reaction solution gradually turns yellow and eventually turns brown oily liquid. The reaction was monitored by TLC, eluent petroleum ether and ethyl acetate mixture (V: V=2:1). After the reaction, the process on a rotary evaporator after the reaction was purified by column chromatography on silica crude product with ethyl acetate: petroleum ether $(\mathrm{V}: \mathrm{V}=1: 10)$ was to afford $0.6222 \mathrm{~g}$ of brown oily liquid .

According to the above experimental procedure, ratio of reactants and the temperature of single factor experiment were studied as effects on the reaction.

N '- (2- cyanophenyl) -N, N- dimethyl-formamidine: brown oily liquid, yield $76.8 \%$. ${ }^{1} \mathrm{H}$ NMR $\left(\mathrm{CDCl}_{3}, 400 \mathrm{MHz}\right) \delta: 2.97\left(\mathrm{~s}, 6 \mathrm{H}, \mathrm{CH}_{3}\right), 6.88(\mathrm{dd}, J=8.0 \mathrm{~Hz}, \mathrm{~J}=8.0 \mathrm{~Hz}, 2 \mathrm{H}, \mathrm{Ar}-\mathrm{H}), 7.32(\mathrm{~s}, 1 \mathrm{H}, \mathrm{Ar}-\mathrm{H})$, 7.43(s, $1 \mathrm{H}, \mathrm{Ar}-\mathrm{H}), 7.51(\mathrm{~s}, 1 \mathrm{H}, \mathrm{CH}=\mathrm{N}) .{ }^{1} \mathrm{C} \mathrm{NMR}\left(\mathrm{CDCl}_{3}, 100 \mathrm{MHz}\right) \delta: 34.33,40.09,106.47,118.60$, $119.44,121.77,132.87,133.28,153.58,155.06$. ESI-MS $m / z: 174.10[\mathrm{M}+\mathrm{H}]^{+}$.

\section{Synthesis of N- (4-acetyl-phenyl) quinazolin-4-amine}

$0.8661 \mathrm{~g}(5.0 \mathrm{mmol}) \mathrm{N}$ '- (2- cyanophenyl) -N, N- dimethyl-formamidine, $0.6758 \mathrm{~g}$ (5.0 mmol) of amino acetophenone, and $5.0 \mathrm{~mL}$ glacial acetic acid $(99.5 \%)$ were sequentially added into $25 \mathrm{~mL}$ three-neck flask. The three-necked flask was fitted with a magnetic stirrer, a thermometer, ball condenser and heated to reflux. At the start of heating, the slow dissolution of the amino acetophenone, the reaction solution turned bright yellow and the red-brown, as the temperature was slowly raised, the solution turns orange-red, with the increase of the reaction time, the final color of the solution turns yellow. The reaction was monitored by TLC, eluent petroleum ether and ethyl acetate mixture $(\mathrm{V}: \mathrm{V}=1: 1)$. After completion of the reaction, the reaction mixture was cooled to room temperature, with an appropriate amount of aqueous ammonia to adjust the $\mathrm{pH}$ to 8-9, filtration, washing the filter cake with a suitable amount of distilled water, suction filtered, the crude product followed by acetone, ethanol, $\mathrm{CH}_{2} \mathrm{Cl}_{2}$ and washed to give $1.0685 \mathrm{~g}$ of yellow solid.

According to the above experimental procedure, experiments were carried out at different temperatures to investigate its effect on the reaction.

N-(4-acetyl-phenyl)quinazolin-4-amine: yellow solid, yield 81.2\%. m.p. 206 208 ${ }^{\circ}$; ${ }^{1} \mathrm{H} \mathrm{NMR}$ $\left(\mathrm{DMSO}-d_{6}, 400 \mathrm{MHz}\right) \delta: 2.57\left(\mathrm{~s}, 3 \mathrm{H}, \mathrm{CH}_{3}\right), 7.68(\mathrm{t}, J=8.0 \mathrm{~Hz}, 1 \mathrm{H}, \mathrm{Ar}-\mathrm{H}), 7.83(\mathrm{~d}, J=6.0 \mathrm{~Hz}, 1 \mathrm{H}$, $\mathrm{Ar}-\mathrm{H}), 7.92(\mathrm{t}, J=6.0 \mathrm{~Hz}, 1 \mathrm{H}, \mathrm{Ar}-\mathrm{H}), 7.80(\mathrm{~d}, J=4.0 \mathrm{~Hz}, 2 \mathrm{H}, \mathrm{Ar}-\mathrm{H}), 8.12(\mathrm{~d}, J=4.0 \mathrm{~Hz}, 2 \mathrm{H}, \mathrm{Ar}-\mathrm{H})$, 8.61(d, $J=4.0 \mathrm{~Hz}, 1 \mathrm{H}, \mathrm{Ar}-\mathrm{H}), 8.74(\mathrm{~s}, 1 \mathrm{H}, \mathrm{CH}=\mathrm{N}), 10.05(\mathrm{~s}, 1 \mathrm{H}, \mathrm{NH}) .{ }^{13} \mathrm{C}$ NMR (DMSO- $d_{6}, 100$ MHz) $\delta$ : 26.47, 115.31, 120.79, 123.07, 126.57, 127.94, 129.07, 131.61, 133.31, 143.90, 149.83, 154.19, 157.46, 196.54. ESI-MS $m / z: 264.15[\mathrm{M}+\mathrm{H}]^{+}$.

Synthesis of 4-(4'-quinazolin-ylamino) phenyl-4-(N, N-dimethylamino) phenyl propenone

$1.3165 \mathrm{~g}(5 \mathrm{mmol}) \mathrm{N}$ - (4- acetyl-phenyl) quinazolin-4-amine and $20 \mathrm{~mL}$ of absolute ethanol was added to a $50 \mathrm{~mL}$ three necked flask, cooled to room temperature after heated to dissolve. $0.7460 \mathrm{~g}$ (5 mmol) of dimethylaminobenzaldehyde was also added, shake well, then slowly dropping 10\% $\mathrm{NaOH}$ solution to a three-necked flask and stirred at room temperature. Just $10 \% \mathrm{NaOH}$ solution 
was added, the reaction solution changed from yellow to brown as the reaction time increases, the final color of the solution turns reddish brown. The reaction was monitored by TLC, eluent petroleum ether: ethyl acetate $(\mathrm{V}: \mathrm{V}=1: 1)$. After completion of the reaction, to give red-brown turbid solution, filtration, drying, red-brown solid was purified by silica gel thin-layer chromato- graphy, eluent, ethyl acetate: petroleum ether $(\mathrm{V}: \mathrm{V}=5: 1)$, to give a red-brown solid $0.2151 \mathrm{~g}$.

4-(4'-quinazolin-ylamino)phenyl-4-(N, N-dimethylamino) phenyl propenone : red-brown solid, yield 10.9\%. m.p. $>250^{\circ} \mathrm{C}$; ${ }^{1} \mathrm{H} \mathrm{NMR}\left(\mathrm{DMSO}-d_{6}, 400 \mathrm{MHz}\right) \delta: 2.97\left(\mathrm{~s}, 6 \mathrm{H},-\mathrm{CH}_{3}\right), 7.04(\mathrm{~s}, 2 \mathrm{H}$, Ar-H), 7.22(s, 2H, Ar-H), 7.55(s, 2H, Ar-H), 7.66(d, $J=7.0 \mathrm{~Hz}, 1 \mathrm{H},-\mathrm{CH}=), 7.68(\mathrm{~s}, 1 \mathrm{H}, \mathrm{Ar}-\mathrm{H})$, 7.76(s, 1H, Ar-H), 7.83(d, J=7.6 Hz, 1H, Ar-H), 7.93(s, 1H, Ar-H), 8.01 (d, J=7.0 Hz, 1H, $-\mathrm{CH}=)$, $8.18(\mathrm{~s}, 2 \mathrm{H}, \mathrm{Ar}-\mathrm{H}), 8.46(\mathrm{~s}, 1 \mathrm{H},-\mathrm{CH}=\mathrm{N}), 9.40(\mathrm{~s}, 1 \mathrm{H},-\mathrm{NH}-) .{ }^{13} \mathrm{C}$ NMR (DMSO-d, $\left.100 \mathrm{MHz}\right) \delta$ : 40.2, 115.2, 116.3, 116.5, 119.5, 124.8, 126.3, 127.4, 127.9, 129.4, 130.6, 133.9, 145.3, 147.2, 148.8, $149.9,151.5,156.4,168.9,189.7$. ESI-MS $m / z: 395.20[\mathrm{M}+\mathrm{H}]^{+}$.

\section{Results and Discussions}

Effect of material ratio on the synthesis of $\mathbf{N}^{\prime}$-(2-cyanophenyl)-N, $\mathrm{N}$ - dimethyl formamidine

At $85{ }^{\circ} \mathrm{C}$, different material ratio of anthranilic nitrile and DMF-DMA molar ratio of 1:1 and 1:2 was used to synthesis N' -(2- cyanophenyl) -N, N- dimethyl-formamidine. Investigate the influence of different material ratio on the experiment, the results are shown in table 1.

Table 1 The influence of material ratio on the experimental results

\begin{tabular}{ccccl}
\hline NO. & $\begin{array}{c}\text { Temperature/ } \\
{ }^{\circ} \mathrm{C}\end{array}$ & $\begin{array}{c}\text { Material } \\
\text { ratio }\end{array}$ & Time/h & $\begin{array}{l}\text { The reaction } \\
\text { process }\end{array}$ \\
\hline 1 & 85 & $1: 1$ & 24 & Not completely \\
2 & 85 & $1: 2$ & 1 & completely \\
\hline
\end{tabular}

As can be seen from Table 1: When anthranilic nitrile and DMF-DMA molar ratio of 1: 1, even if $24 \mathrm{~h}$ the reaction is not complete; when the material ratio is: 1:2, Reaction $1 \mathrm{~h}$ was over. So anthranilic nitrile and DMF-DMA molar ratio of 1: 2 was chosen as experimental condition.

Effect of temperature on the synthesis of $N$ '-(2-cyanophenyl)-N, $N$-dimethyl formamidine

Anthranilic nitrile and DMF-DMA molar ratio of 1: 2, investigated the effects of different reaction temperature on the results shown in Table 2.

It can be seen from Table 2 that temperature has a great effect on the reaction. The temperature was gradually increased with the decreased reaction time. When the temperature rises from $25{ }^{\circ} \mathrm{C}$ to $85^{\circ} \mathrm{C}$, while reducing the time required to yield increase, but when the temperature reaches $105{ }^{\circ} \mathrm{C}$, although the reaction time is reduced, but the yield is reduced. So $85{ }^{\circ} \mathrm{C}$ was chosen as reaction temperature.

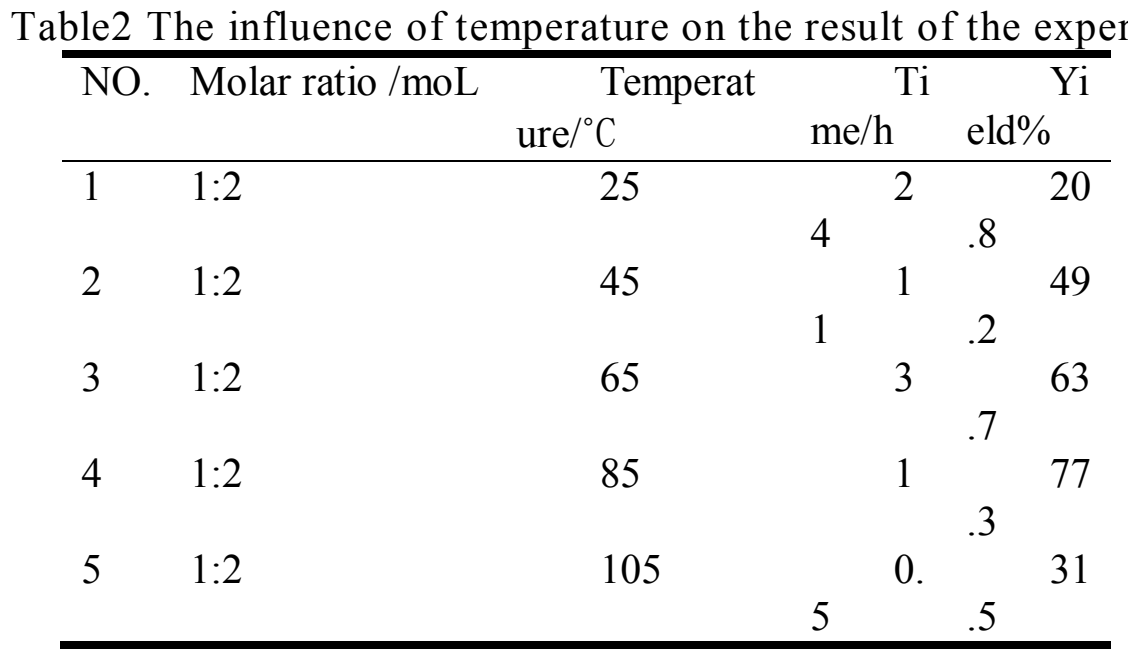




\section{Effect of temperature on synthesis of N- (4- acetyl-phenyl) quinazolin-4- amine}

Table 3 Effect of temperature on synthesis of N- (4- acetyl-phenyl) quinazolin-4-amine

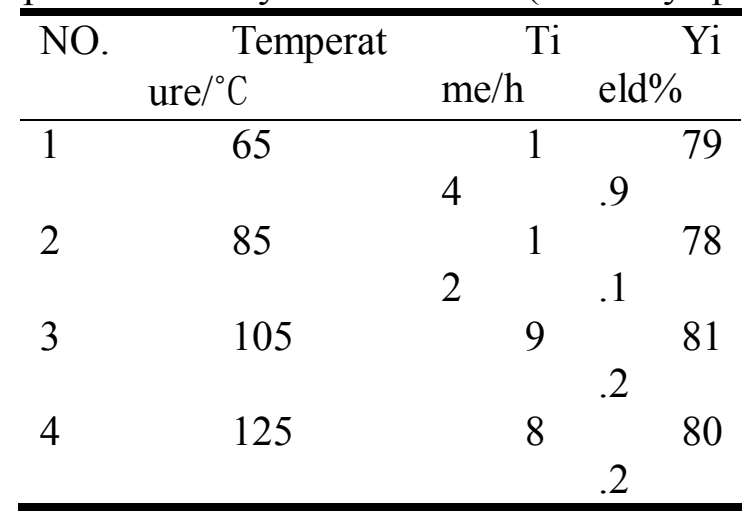

The molar ratio of aminoacetophenone and $\mathrm{N}^{\prime}-(2-$ cyanophenyl $)-\mathrm{N}, \mathrm{N}$ - dimethyl formamidine is 1: 1, other reaction conditions remain unchanged, effects of different temperatures on the experimental results was investigated. The results are shown in Table 3.

As can be seen from Table 3, the effect of reaction temperature on the yield is not obvious, while have a greater impact on reaction time. $105^{\circ} \mathrm{C}$ condition was selected as the experimental reaction.

Separation and purification of 4-(4'-quinazolin-ylamino) phenyl -4- (N, N- dimethylamino) phenyl propenone

The synthesis of the target product with $\mathrm{N}$-(4-acetyl-phenyl) quinazolin -4-amine and p-dimethylaminobenzaldehyde as the materials, ethanol as the solvent, the reaction conditions of $10 \% \mathrm{NaOH}$, the yield of product is low, the reasons maybe: First, the solubility of material $\mathrm{N}$-(4-acetyl phenyl) quinazolin-4-amine is not good; the second is a lot of side effects, separation and purification difficult.

\section{Conclusions}

4-(4'-quinazolin-ylamino)phenyl-4-(N,N-dimethylamino)phenyl propenyl ketone with total yield of $68.0 \%$ was synthesized with O-aminobenzonitrile and $\mathrm{N}, \mathrm{N}$ - dimethylformamide dimethyl acetal as a starting material, the synthesis of $\mathrm{N}$-(2-cyanophenyl)-N,N-dimethyl-formamidine, 2-aminoben zonitrile and DMF-DMA as a starting material, through a three-step reaction. Structural characterization of intermediates and target compounds was using ${ }^{1} \mathrm{H} \mathrm{NMR},{ }^{13} \mathrm{C} \mathrm{NMR}$ and mass spectrometry.

Compared to the project team reported in the literature [16], it can be seen that when synthesis Charles Seoul derivatives, different structures of aldehydes and ketones can influence the difficulty of the reaction and reaction yield.

\section{Acknowledgements}

This work was supported by the the Open Fund of Master Pilot Construction of Chemical Subject (NO.HXY1303, NO.HXY1304).

\section{References}

[1] Garofalo, L. Goossens, B. Baldeyrou, et al. J. Med. Chem., 2010, 53 (22): 8089-8103.

[2] H. P. Yan, G. P. Ouyang. Chin J. Org. Chem. 2011, 31(6): 901-907. (In Chinese)

[3] H. P. Yan, G. B. Li, S. Y. Chen, et al. Fin. Chem., 2012, 29(1):52-56. (In Chinese)

[4] H. P. Yan, D. S. Huang, J.C. Zhang. Advanced Materials Research. 2012 (634-638): 1215-1218. 
[5] H. P. Yan, G. P. Ouyang. Advanced Materials Research. 2013 (781-784):1003-1006.

[6] H. P. Yan, B. Zhou, G. Z. Gou, et al. Asian Journal of Chemistry. 2015, 27( 7):2460-2462.

[7] A. Chilin, M. T. Conconi, G. Marzaro, et al. J. Med. Chem. 2010, 53: 1862-1866.

[8] Chilin, G. Marzaro, S. Zanatta, et al. Tetrahedron Lett. 2007, 48: 3229-3231.

[9] X. Cai, H. X. Zhai, J. Wang, et al. J. Med. Chem. 2010, 53: 2000-2009.

[10] G. Marzaro, A. Guiotto, G. Pastorini, et al. Tetrahedron, 2010, 66: 962-968.

[11]J. Xing. M.S. Thesis, Tianjin Medical University, Tianjin, 2009(In Chinese).

[12] R. Laliberte, D. J. Campbell, F. Bruderlein. Can. J. Pharm. Sci., 1967, 2(2): 37-43.

[13]K. Q. He, G. F. Cheng, F. D. Xi, et al. Acta Pharm. Sin., 1996, 11, 878-880. (In Chinese)

[14]M. Oumi, D. Maurice, M. H.Gordon. Spectrochim. Acta Part A, 1999, 55, 525-537.

[15] S. Padhye, A. Ahmad, N. Oswal, et al. J. Hematol. Oncol., 2009, 2: 38-40.

[16]H. P. Yan, D. S. Huang, J.C. Zhang et al. Advanced Materials Research.2014(1033-1034): 81-84. 